\title{
Identification of Malay vernacular spatial features within Malay vernacular houses
}

\begin{abstract}
Contemporarily, the quality of residential functional spaces has been mostly based on style and modernity rather than the tradition of that particular regional context. With the rapid modernization of Malaysia, the kampong house (Malay vernacular houses) and other preexisting vernaculars have been replaced by modern architecture. Moreover, the consideration of vernacular architectural factors during the modern design process has been decreased. Accordingly, various aspects of kampong, which identified it as a major vernacular value, have been lost inside contemporary functional spaces. Therefore, the neglected fundamental features of functional spaces during the design process are thought to be these vernacular functional spatial features. In this research, a qualitative case study research method will be utilized to study those vernacular architectural features of Malaysian vernacular houses. The study is limited to studying the spatial characteristics of functions and spaces based on local needs, which will influence the quality of functional spaces. The Salinger house which is a unique symbol of Malaysian vernacular architecture has been selected as a single case study for this research. The data which will be collected from direct observation will be analyzed through pattern matching to corroborate with literature findings. The study is limited to vernacular architectural features of Malaysia which can be utilized for contemporary residential functional spaces during the design process. This research contributes toward the identification of vernacular architectural features that could be integrated successfully in the design process. Hence, the integration of these vernacular architectural aspects during the design process will influence the quality of functional spaces. Correspondingly, functional spaces will be intertwined with vernacular functional spatial features that will address the local needs in terms of their vernacular features.
\end{abstract}

Keyword: Vernacular Architecture, Vernacular Architectural Features, Functional Spaces, Kampong House 